\title{
Insufficient Flow or Underinfusion
}

National Cancer Institute

\section{Source}

National Cancer Institute. Insufficient Flow or Underinfusion. NCI Thesaurus. Code C62823.

Problem associated with an insufficient dose of therapeutic agents, e.g., drugs or fluids being delivered into a patient under positive pressure. 